\title{
Temporal trends in female breast cancer mortality in Brazil and correlations with social inequalities: ecological time-series study
}

\author{
Carolina Maciel Reis Gonzaga ${ }^{1}$, Ruffo Freitas-Junior ${ }^{2,7^{*}}$, Maria-Paula Curado 1,3,4, Ana-Luiza Lima Sousa', \\ José-Augusto Souza-Neto ${ }^{5}$ and Marta Rovery Souza ${ }^{6}$
}

\begin{abstract}
Background: Breast cancer is the most common cause of death from cancer in women in less developed regions. Therefore, the objective of this study was to provide data on the temporal trends in female breast cancer mortality between 1990 and 2011 and to evaluate its association with the social inequalities present in Brazil.

Methods: Breast cancer mortality data and estimates for the resident population were obtained from the Brazilian National Health Service database for the 1990-2011 period. Age-standardized mortality rates were calculated (20-39, 40-49, 50-69 and $\geq 70$ years) by direct standardization using the 1960 standard world population. Trends were modeled using joinpoint regression model and linear regression. The Social Exclusion Index and the Human Development Index were used to classify the 27 Brazilian states. Pearson's correlation was used to describe the association between the Social Exclusion Index and the Human Development and the variations in mortality rates in each state.

Results: Age-standardized mortality rates in Brazil were found to be stable (annual percent change $[A P C]=0.3$; 95\% Cl: $-0.1-0.7)$ between 1994 and 2011. Considering the Brazilian states, significant decreases in mortality rates were found in Rio Grande do Sul, Rio de Janeiro and São Paulo. Increases in mortality rates were most notable in the states of Maranhão (APC $=11.2 ; 95 \% \mathrm{Cl}: 5.8$ - 16.9), Piauí (APC =9.8; 95\% Cl: $7.6-12.1$ ) and Paraíba (APC $=9.3 ; 95 \% \mathrm{Cl}: 6.0$ - 12.8). There was a statistically significant correlation between Social Exclusion Index and a change in female breast cancer mortality rates in the Brazilian states between 1990 and 2011 and between Human Development Index and mortality between 2001 and 2011.
\end{abstract}

Conclusions: Female breast cancer mortality rates are stable in Brazil. Reductions in these rates were found in the more developed states, possibly reflecting better healthcare.

Keywords: Breast cancer, Mortality, Trends, Brazil, Socioeconomic factors

\section{Background}

Breast cancer is the most common cause of death from cancer in women in less developed regions $(324,000$ deaths; $14.3 \%$ of the total) and the second cause of death from cancer in women after lung cancer in the more developed regions (198,000 deaths). Despite the high incidence of the disease in the developed world, mortality rates are much lower because of favorable survival rates

\footnotetext{
* Correspondence: ruffoj@@terra.com.br

${ }^{2}$ Department of Obstetrics and Gynecology, Federal University of Goiás (UFG), Goiânia, Brazil

${ }^{7}$ Alameda das Rosas, 533, Setor Oeste, 74110-060 Goiânia, GO, Brazil

Full list of author information is available at the end of the article
}

[1]. Data collected in the United States over the past two decades show that breast cancer mortality rates have decreased by more than 30\% since their peak in 1991; nevertheless, breast cancer is still the most common cause of death from cancer in women of 20 to 59 years of age [2].

In Brazil, mortality rates range from 14 per 100,000 in the south and southeast to 6.6 per 100,000 in the north of the country. Nonetheless, a significant decrease has been seen in the southeast since 1997 (APC $=-0.9 \%)$ and a non-significant decrease in the south of the country. In the other regions, although rates were lower, there was a tendency towards an increase. The highest 
mortality rates were found in the state of Rio de Janeiro (18.8 in 1994) and in the Federal District (18.4 in 2006) [3]. In urban areas, a significant decrease in mortality was found in five cities compared to only one rural district. Breast cancer mortality increased in the majority of rural regions in Brazil with the exception of some areas in the south and southeast of the country. A possible reason for this disparity may be that access to treatment is more difficult for patients living in rural areas [4].

Advances in treatment have considerably improved the prognosis of breast cancer in recent decades, with survival rates reaching approximately $90 \%$ for white women in the United States [2]. Paradoxically, improvements in treatment increased inequalities in health resources between women living in rich countries and those living in middle to low income countries. The most important factors are the availability of drugs at an accessible cost and of centers of excellence to guarantee the efficacy and safety of treatment [5].

International initiatives have highlighted the need to improve breast cancer treatment in developing countries [6], with the objective of decreasing mortality by reducing disparities in the access to treatment and diagnostic methods. The high mortality rates in these countries are known to be a consequence of the fact that diagnosis is made at an advanced stage and that resources for treatment are scarce.

The Brazilian population varies insofar as their ethnic origin, culture and socioeconomic conditions are concerned. For this reason, providing high quality healthcare throughout the entire country is a challenge [7], and there is a need for further epidemiological studies on breast cancer. Therefore, the objective of this study was to provide data on the temporal trends in female breast cancer mortality between 1990 and 2011 and to evaluate its association with the social inequalities present in Brazil.

\section{Methods}

Cancer mortality data and estimates for the resident population from 20 to 39,40 to 49,50 to 69 and $\geq 70$ years of age for the 1990 to 2011 period were obtained from the Ministry of Health's database (DATASUS) [8]. Breast cancer deaths were coded according to the International Classification of Diseases (ICD). The ninth revision of the ICD (ICD-9) was used for the 1990-1995 period (ICD code 174), while the $10^{\text {th }}$ revision was used for the 19962011 period (ICD code C50). Age-standardized mortality rates for women of 20 years of age or more were obtained by direct standardization based on the 1960 world standard population. Variations in mortality were modeled using standard linear regression methods, with the age-standardized mortality coefficient as the dependent variable and the calendar year as the independent variable.
Trends in age-adjusted breast cancer death rates were estimated using joinpoint regression, which involves fitting a series of joined straight lines on a logarithmic scale to the trends in the annual age-adjusted mortality rates [9] using the Joinpoint Regression Program (version 4.0). A maximum of 3 joinpoints was allowed in models for the period 1990 through 2011. The resulting trends were described by the slope of the line segment or the annual percent change (APC). The average APC (AAPC) was estimates as a weighted geometric average of the APCs, with the weights equal to the length of each line segment during the prespecified, fixed interval. The 95\% confidence intervals (95\% CIs) were calculated for each estimated APC. If these intervals excluded zero, then the APCs were statistically significant $(\mathrm{p}<.05)$.

The Social Exclusion Index (SEI) and the Human Development Index (HDI), which ranges from 0 (worst) to 1 (best), were used to classify the 27 Brazilian states. The human development index (HDI) is a composite statistic of life expectancy, education and income indices used to rank countries into four tiers of human development, taking into consideration a concept of well-being viewed in terms of capability. The lowest HDI was in the state of Alagoas (0.631), while the highest was in the Federal District (0.824) (Figure 1a). The SEI was based on three dimensions: suitable life conditions, knowledge and youth vulnerability, as described previously [10]. The lowest SEI was in the state of Maranhão (0.197) and the highest in the Federal District (0.850) (Figure 1b).

Pearson correlation coefficients were used to describe the correlation between the SEI and the variations in mortality rates in each Brazilian state for the entire evaluation period, the HDI (2000) for the 1990-2000 period and the HDI (2010) for the 2001-2010 period. For all the statistical tests, a type $1(\alpha)$ error of $5 \%$ was adopted.

This project has been approved by the Ethics Committee on Human and Animal Research of the Hospital of the Federal University of Goiás (Protocol number 75793).

\section{Results}

Between 1990 and 2011, 195,596 deaths from breast cancer were registered for Brazilian women of 20 years of age or more. By age group, the highest rates were in the group of Brazilian women of 70 years of age or older (Table 1). In Brazil, the highest age-adjusted mortality rate was in $2006(12.7 / 100,000)$ and the lowest in 1991 $(10.2 / 100,000)$. The highest mortality rate in the entire period evaluated was found in the state of Rio de Janeiro $(17.2 / 100,000)$ and the lowest in the state of Maranhão $(3.2 / 100,000)$ (Figure 2).

A statistically significant increase in breast cancer mortality rates in Brazil, was found for the following age groups: $20-39$ years $(\mathrm{APC}=0.7 ; 95 \%$ CI: $0.3-1.1, \mathrm{p}<0.01), 50-69$ 


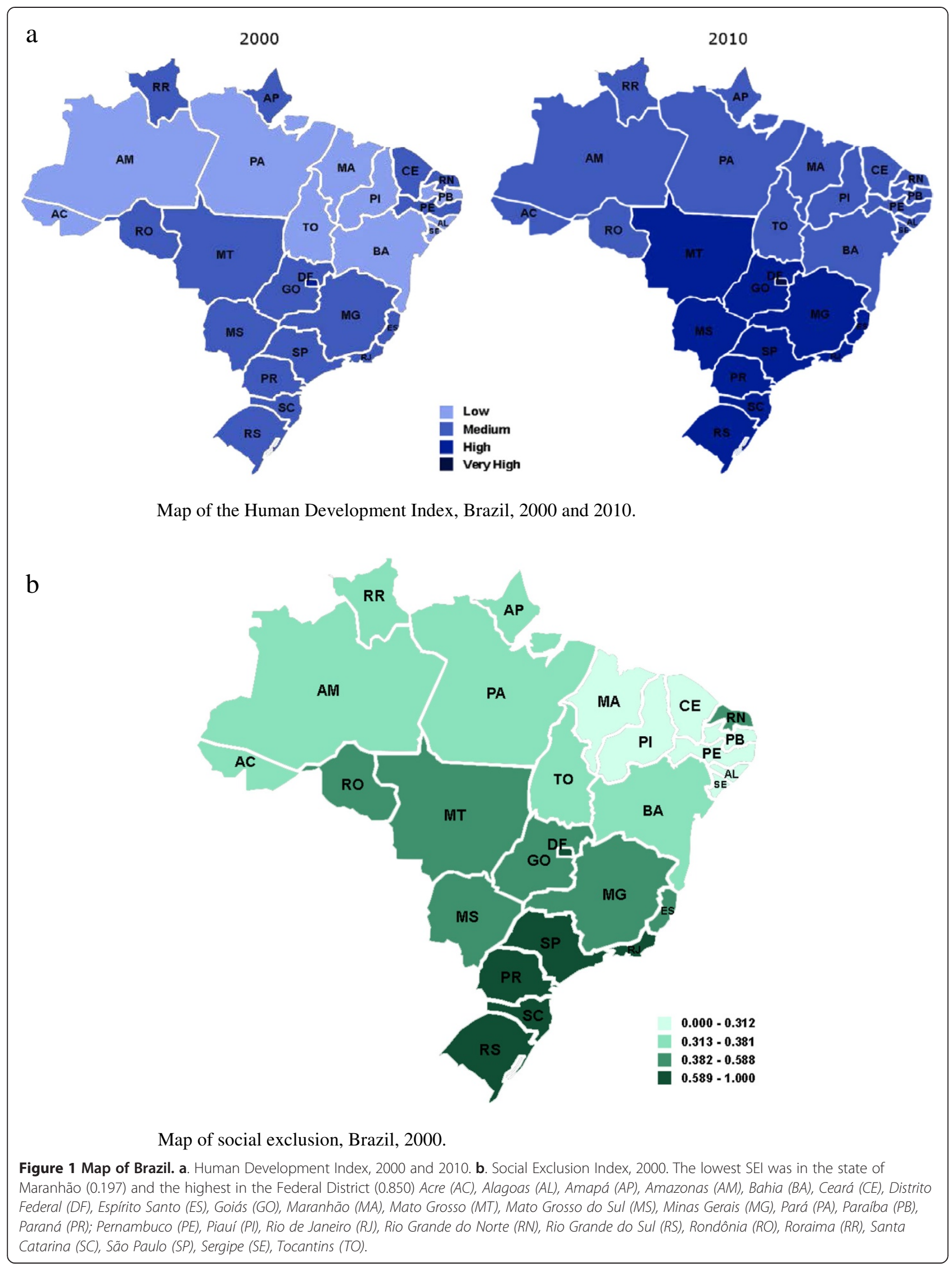


Table 1 Age-specific and age-standardized world female breast cancer mortality rates according to year: Brazil, 1990-2011

\begin{tabular}{|c|c|c|c|c|c|}
\hline \multirow{3}{*}{ Year } & \multicolumn{4}{|c|}{ Mortality rate (per 100.000) } & \multirow{3}{*}{$\begin{array}{l}\text { Age-adjusted } \\
\geq 20 \text { years }\end{array}$} \\
\hline & \multicolumn{4}{|c|}{ Age-specific } & \\
\hline & $\begin{array}{l}20-39 \\
\text { years }\end{array}$ & $\begin{array}{l}40-49 \\
\text { years }\end{array}$ & $\begin{array}{l}50-69 \\
\text { years }\end{array}$ & $\geq 70$ years & \\
\hline 1990 & 2.5 & 16.0 & 34.0 & 56.7 & 10.3 \\
\hline 1991 & 2.3 & 16.3 & 33.5 & 56.7 & 10.2 \\
\hline 1992 & 2.4 & 16.5 & 34.6 & 57.1 & 10.5 \\
\hline 1993 & 2.4 & 17.8 & 35.9 & 62.3 & 11.0 \\
\hline 1994 & 2.7 & 18.5 & 37.5 & 65.5 & 11.6 \\
\hline 1995 & 2.7 & 17.7 & 36.9 & 65.6 & 11.4 \\
\hline 1996 & 2.5 & 16.3 & 34.5 & 62.0 & 10.7 \\
\hline 1997 & 2.4 & 17.9 & 36.5 & 65.5 & 11.3 \\
\hline 1998 & 2.6 & 17.7 & 37.4 & 71.7 & 11.7 \\
\hline 1999 & 2.7 & 17.7 & 37.0 & 72.8 & 11.7 \\
\hline 2000 & 2.5 & 16.7 & 33.8 & 62.5 & 10.6 \\
\hline 2001 & 2.5 & 16.7 & 35.3 & 64.3 & 10.9 \\
\hline 2002 & 2.6 & 16.7 & 37.0 & 64.8 & 11.3 \\
\hline 2003 & 2.5 & 17.5 & 36.9 & 70.7 & 11.5 \\
\hline 2004 & 2.6 & 17.7 & 38.9 & 72.2 & 11.9 \\
\hline 2005 & 2.5 & 18.3 & 39.2 & 74.5 & 12.1 \\
\hline 2006 & 2.6 & 18.1 & 41.4 & 79.8 & 12.7 \\
\hline 2007 & 2.6 & 16.5 & 35.4 & 68.2 & 11.1 \\
\hline 2008 & 2.8 & 17.1 & 37.2 & 70.1 & 11.6 \\
\hline 2009 & 2.9 & 17.0 & 36.0 & 69.1 & 11.4 \\
\hline 2010 & 2.9 & 17.2 & 37.2 & 69.4 & 11.6 \\
\hline 2011 & 3.0 & 17.9 & 38.0 & 72.2 & 12.0 \\
\hline
\end{tabular}

years $(\mathrm{APC}=0.4 ; 95 \% \mathrm{CI}: 0.1-0.8, \mathrm{p}<0.01)$ and 70 years of age or older $(\mathrm{APC}=1.0$; 95\% CI: $0.6-1.5, \mathrm{p}<0.01)$. There was also a trend towards an increase in the 40-49 years age group; however this increase was not statistically significant: $(\mathrm{APC}=0.2 ; 95 \% \mathrm{CI}:-0.0-0.5, \mathrm{p}=0.1)$.

Female breast cancer mortality rates have remained stable (APC $=0.3$; 95\% CI: $-0.1-0.7$ ) in Brazil, between 1994 and 2011 (Table 2). A statistically significant decrease in mortality was found in the states of Rio Grande do Sul, Rio de Janeiro and São Paulo (Table 2).

Increasing trends in mortality rates were most notable in the states of Maranhão (APC $=11.2$; 95\% CI: $5.8-$ 16.9) between 2002 and 2011, Piauí (APC $=9.8 ; 95 \% \mathrm{CI}$ : 7.6 - 12.1), between 1997 and 2011 and Paraíba $(\mathrm{APC}=$ 9.3; 95\% CI: 6.0 - 12.8) between 1999 and 2011 (Table 2).

Linear regression models showed disparities in female breast cancer mortality trends in Brazil. There was no statistically significant correlation between HDI and a change in the female breast cancer mortality rates in Brazil $(\mathrm{r}=0.28 ; \mathrm{p}=.156)$ between 1990 and 2000 (Figure 3a). However, for the 2001-2011 period, a statistically significant correlation was found between HDI and the change in female breast cancer mortality rates in the country $(\mathrm{r}=-0.79 ; \mathrm{p}<.001)$ (Figure $3 \mathrm{~b})$ and also between SEI and mortality $(\mathrm{r}=-0.75 ; \mathrm{p}<0.001)$ for the overall period (Figure 4).

\section{Discussion}

To the best of our knowledge, this is the first report to analyze the temporal trends in female breast cancer mortality in Brazil and to correlate them with social inequalities. The study of mortality trends is useful for monitoring changes in the epidemiological profile of the population.

The female breast cancer mortality rates in Brazil described in the present study are similar to rates found earlier in Chile, Costa Rica, Cuba, Puerto Rico and Venezuela [11], values expected for developing countries [1]. However, they are higher than rates found in Colombia, Ecuador and Mexico $(<10 / 100,000)$ [11]. Female breast cancer mortality trends have remained stable in the country since 1994, this finding being in agreement with reports from another study $(\mathrm{APC}=0.4 \%)$ [3].

A marked disparity was found between the different Brazilian states with respect to mortality rates, which ranged from $2-5 / 100,000$ in the less developed areas of the country to $12-18 / 100,000$ in the more developed regions. Although rates were higher in these states, there was a significant decrease in mortality rates in Rio Grande do Sul, Rio de Janeiro and São Paulo, similar to that seen in developed countries such as the US $(\mathrm{APC}=-1.9 \%)$ [2] and Portugal (APC $=-0.9 \%$ ) [12], and also in some developing countries such as Singapore $(\mathrm{APC}=-1.50 \%)$ [13]. Nevertheless, the mortality rates here are lower than those found in these countries.

One possible hypothesis for the lower breast cancer mortality rates found in Brazil may be under-notification. It is known that the cancer registries cover only $6 \%$ of the Latin American population in comparison to $96 \%$ in the US and 32\% in Europe [14]. There are 17 populationbased cancer registries in the country, 16 of which are located in state capital cities. Data collection varies from registry to registry and also from one year to another within a single registry [8].

Another hypothesis for the patterns of inequality in health found in Brazil with respect to breast cancer mortality may be the lack of available resources for treatment in the less developed states or the inaccessibility of the majority of the population to treatment. In some cases, the situation would be comparable to that found in Nigeria where there is no specific screening program within the national healthcare system and only two hospitals offering tertiary treatment (radiotherapy and 

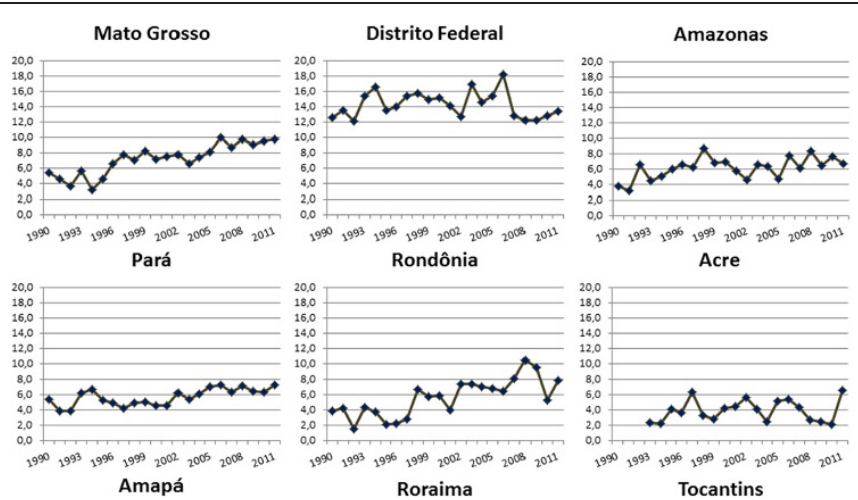

Acre
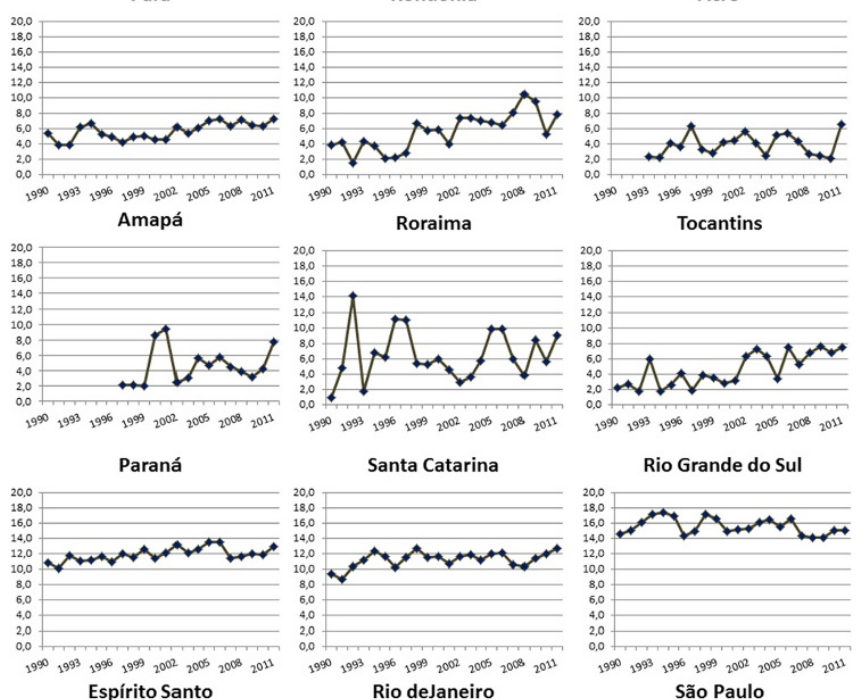

Rio deJaneiro
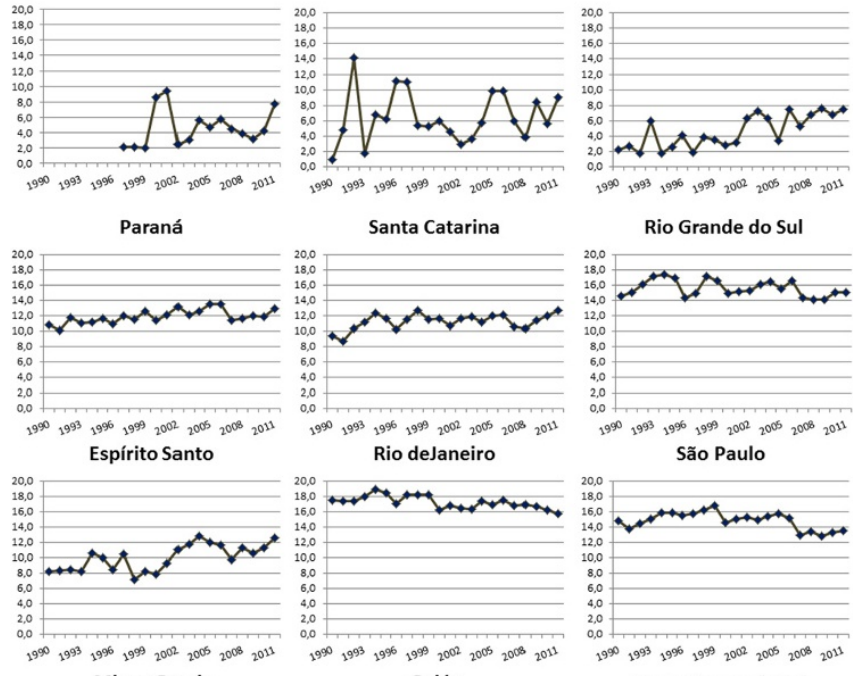

Rio Grande do Sul

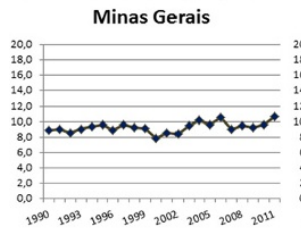

Goiás

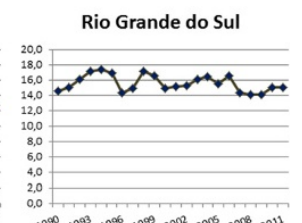

São Paulo

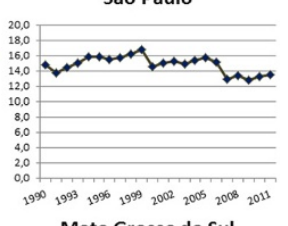

Mato Grosso do Sul
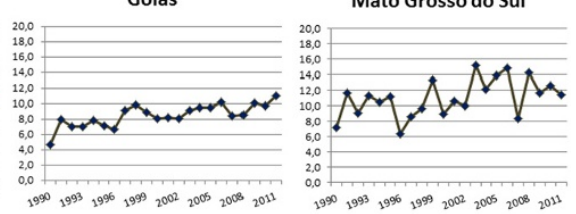

Bahia

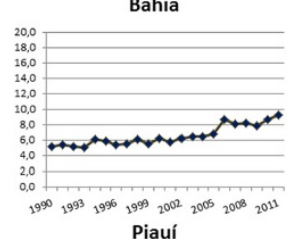

Rio Grande do Norte

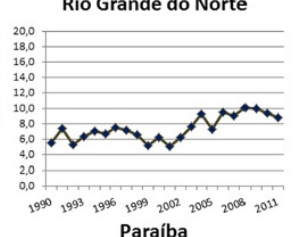

Maranhão
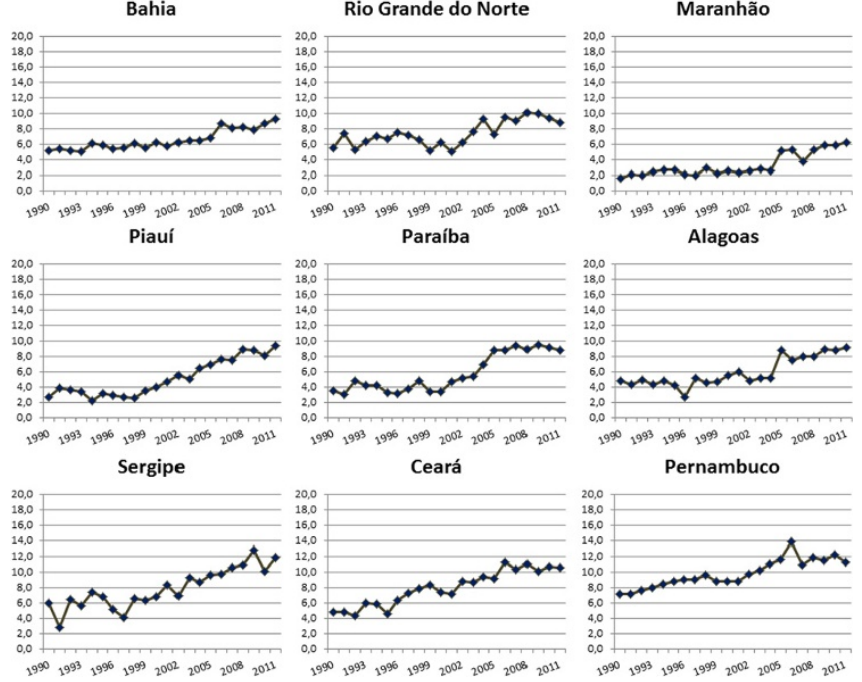

Ceará

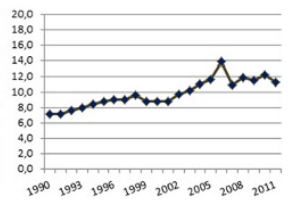

Figure 2 Female breast cancer mortality rates in the states of Brazil from 1990 to 2011. 
Table 2 Temporal trends in mortality from female breast cancer in the states of Brazil between 1990 and 2011

\begin{tabular}{|c|c|c|c|c|c|c|c|}
\hline \multirow[t]{2}{*}{ States } & \multicolumn{3}{|l|}{ Trend 1} & \multicolumn{3}{|l|}{ Trend 2} & \multirow{2}{*}{$\begin{array}{l}\text { AAPC } \\
2002-2011\end{array}$} \\
\hline & Years & APC & (95\% Cl; p-value) & Years & APC & (95\% Cl; p-value) & \\
\hline Paraná & 1990-2005 & $1.2^{*}$ & (0.6 to $1.9 ; p<0.01)$ & $2005-2011$ & -1.2 & $(-3.8$ to $1.4 ; p=0.33)$ & -0.4 \\
\hline Santa Catarina & 1990-1994 & $6.6^{*}$ & $(0.2$ to $13.5 ; p=0.04)$ & 1994-2011 & 0.0 & $(-0.7$ to $0.7 ; p=0.92)$ & 0.0 \\
\hline Rio Grande do Sul & 1990-1993 & 4.6 & $(-4.5$ to $14.6 ; p=0.31)$ & 1993-2011 & $-0.7^{*}$ & $(-1.3$ to $-0.1 ; p=0.01)$ & $-0.7^{*}$ \\
\hline Espírito Santo & 1990-2011 & $1.8^{*}$ & (0.9 to $2.8 ; p<0.01)$ & & & & $1.8^{*}$ \\
\hline Rio de Janeiro & $1990-2011$ & $-0.5^{*}$ & $(-0.8$ to $-0.2 ; p<0.01)$ & & & & $-0.5^{*}$ \\
\hline São Paulo & 1990-1998 & $1.7^{*}$ & $(0.0$ to $3.4 ; p=0.04)$ & $1998-2011$ & $-1.7^{*}$ & $(-2.4$ to $-0.9 ; p<0.01)$ & $-1.7^{*}$ \\
\hline Minas Gerais & $1990-2011$ & $0.5^{*}$ & $(0.0$ to $1.0 ; p=0.04)$ & & & & $0.5^{*}$ \\
\hline Goiás & 1990-2011 & $2.2^{*}$ & $(1.3$ to $3.1 ; p<0.01)$ & & & & $2.2^{*}$ \\
\hline Mato Grosso do Sul & 1990-2011 & $1.7^{*}$ & $(0.2$ to $3.2 ; p=0.02)$ & & & & $1.7^{*}$ \\
\hline Mato Grosso & 1990-2011 & $4.2^{*}$ & $(2.9$ to $4.5 ; p<0.01)$ & & & & $4.2^{*}$ \\
\hline Distrito Federal & 1990-2011 & -0.2 & $(-1.0$ to $0.7 ; p=0.68)$ & & & & -0.2 \\
\hline Amazonas & 1990-2011 & $2.1^{*}$ & (0.6 to $3.7, p<0.01)$ & & & & $2.1^{*}$ \\
\hline Pará & $1990-2011$ & $2.2^{*}$ & $(1.0$ to $3.3, p<0.01)$ & & & & $2.2^{*}$ \\
\hline Rondônia & 1990-2011 & $6.0^{*}$ & (3.4 to $8.7, p<0.01$ ) & & & & $6.0^{*}$ \\
\hline Acre & $1993-2011$ & 0.8 & $(-2.6$ to $4.2 ; p=0.64)$ & & & & 0.8 \\
\hline Amapá & $1997-2011$ & 4.6 & $(-1.9$ to $11.6, p=0.15)$ & & & & 4.6 \\
\hline Roraima & $1990-2011$ & 2.8 & $(-1.6$ to $7.4 ; p=0.20)$ & & & & 2.8 \\
\hline Tocantins & 1990-2011 & $6.3^{*}$ & (3.8 to $8.9 ; p<0.01$ ) & & & & $6.3^{*}$ \\
\hline Bahia & 1990-2001 & 1.2 & $(-0.1$ to $2.6 ; p=0.06)$ & $2001-2011$ & $4.4^{*}$ & $(2.9$ to $6.0 ; p<0.01)$ & $4.4^{*}$ \\
\hline Rio Grande do Norte & 1990-2011 & $2.4^{*}$ & $(1.3$ to $3.6 ; p<0.01)$ & & & & $2.4^{*}$ \\
\hline Maranhão & 1990-2002 & 2.6 & $(-0.7$ to $5.9 ; p<0.11)$ & $2002-2011$ & $11.2^{*}$ & $(5.8$ to $16.9 ; p<0.01)$ & $11.2^{*}$ \\
\hline Piauí & 1990-1997 & -1.6 & $(-7.3$ to $4.5 ; p=0.58)$ & 1997-2011 & $9.8^{*}$ & (7.6 to $12.1 ; p<0.01$ ) & $9.8^{*}$ \\
\hline Paraíba & 1990-1999 & 0.8 & $(-3.9$ to $5.8 ; p=0.72)$ & 1999-2011 & $9.3^{*}$ & (6.0 to $12.8 ; p<0.01$ ) & $9.3^{*}$ \\
\hline Alagoas & 1990-2011 & $4.1^{*}$ & $(2.7$ to $5.5 ; p<0.01)$ & & & & $4.1^{*}$ \\
\hline Sergipe & $1990-2011$ & $4.8^{*}$ & (3.3 to $6.4 ; p<0.01$ ) & & & & $4.8^{*}$ \\
\hline Ceará & 1990-2011 & $4.5^{*}$ & (3.7 to $5.3 ; p<0.01$ ) & & & & $4.5^{*}$ \\
\hline Pernambuco & $1990-2011$ & $2.6^{*}$ & (2.0 to $3.1 ; p<0.01)$ & & & & $2.6^{*}$ \\
\hline Brazil & 1990-1994 & 2.5 & $(-1.3$ to $6.5 ; p=0.18)$ & 1994-2011 & 0.3 & $(-0.1$ to $0.7 ; p=0.13)$ & 0.3 \\
\hline
\end{tabular}

Abbreviations: $A A P C$ average annual percent change; $A P C$ annual percent change.

Joinpoint analyses with up to 1 joinpoints yielding up to 2 trend segments (Trends 1-2).

The AAPC is a weighted average of the APCs that is calculated by joinpoint regression.

Standardized mortality rate per 100,000 women.

*Statistically significant; $p=0.05$.

chemotherapy) [15]. Other problems identified in Brazil include: a lack of information on the disease, the time interval between the first signs/symptoms and first consultation (ranging from 1 to 60 months), delays in diagnosing and treating breast cancer and the time between histopathological diagnosis and the beginning of treatment.

The Amazona Project conducted by the Brazilian Group for Studies in Breast Cancer (GBECAM) collected data from 28 centers, including 4,912 cases of patients diagnosed with breast cancer in 2001 and 2006, representing all the geographical regions of the country and all socioeconomic levels. That study showed the disease to be more advanced at diagnosis in the women treated in public institutions, who had less access to modern therapies and poorer survival compared to patients treated in private institutions [16].

This study evaluated data from nationwide Brazilian surveys, databases and local studies, and its results highlight the gaps in information and the need to acquire further knowledge and to conduct more studies on various aspects. This report provides further information on female breast cancer mortality in Brazil, thus permitting actions to be implemented by enabling predictions to be 


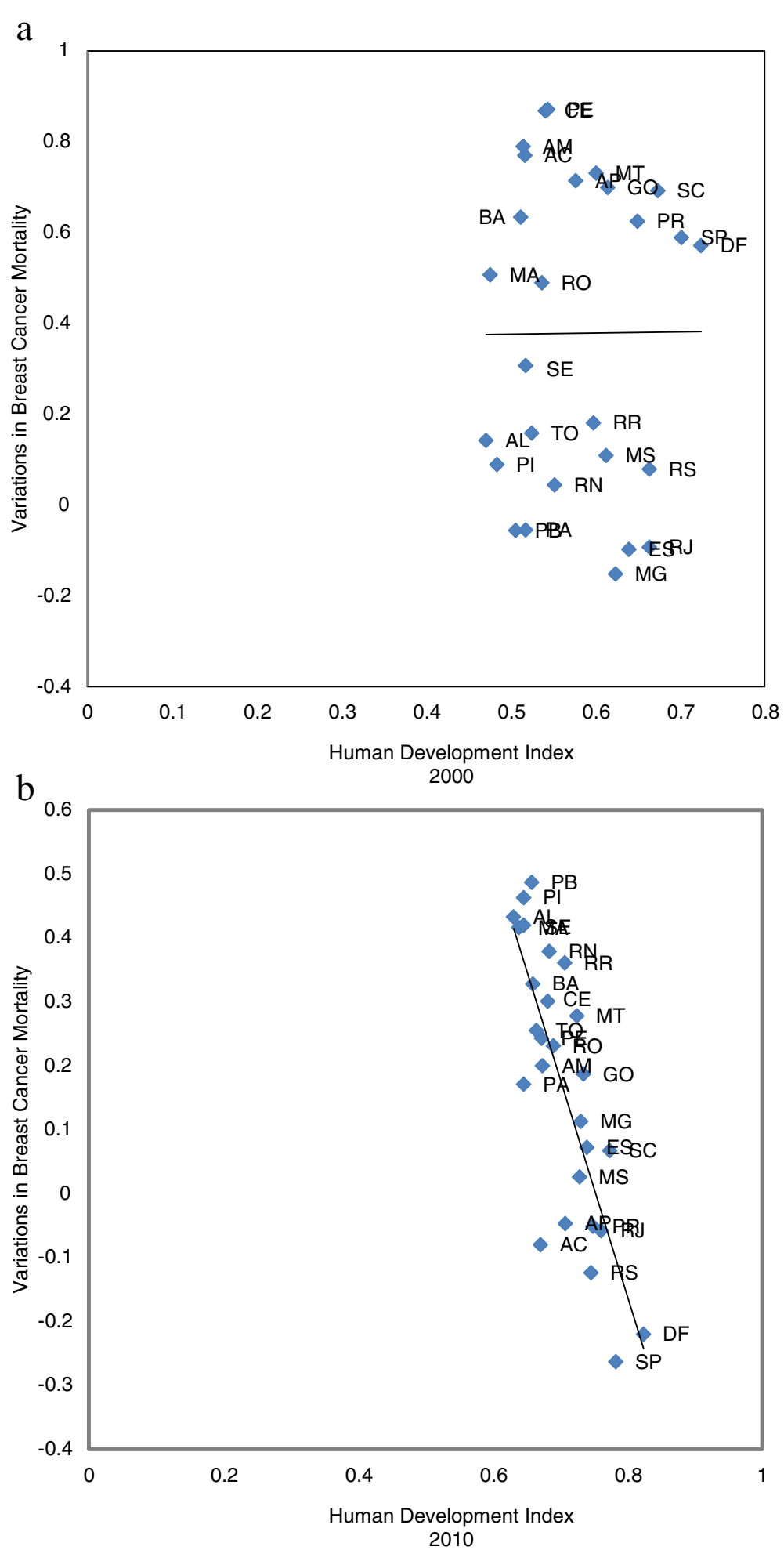

Figure 3 Correlation between the variations in breast cancer mortality rates for women in Brazil. a. Human Development Index (2000) from 1990 to 2000. ( $r=0.28 ; p=.156)$. b. Human Development Index (2010) from 2001 to 2011. ( $r=-0.79 ; p<.001)$. Acre (AC), Alagoas (AL), Amapá $(A P)$, Amazonas (AM), Bahia (BA), Ceará (CE), Distrito Federal (DF), Espírito Santo (ES), Goiás (GO), Maranhão (MA), Mato Grosso (MT), Mato Grosso do Sul (MS), Minas Gerais (MG), Pará (PA), Paraíba (PB), Paraná (PR); Pernambuco (PE), Piauí (PI), Rio de Janeiro (RJ), Rio Grande do Norte (RN), Rio Grande do Sul (RS), Rondônia (RO), Roraima (RR), Santa Catarina (SC), São Paulo (SP), Sergipe (SE), Tocantins (TO). 


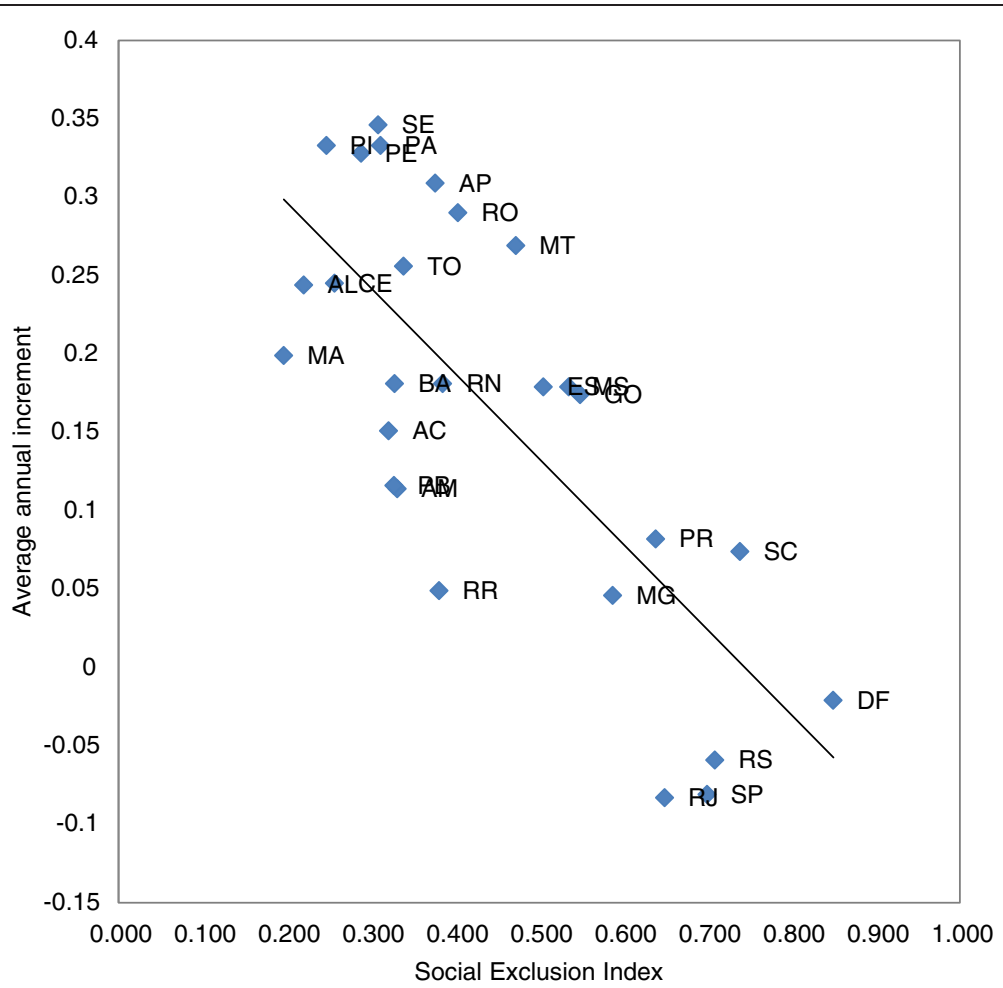

Figure 4 Correlation between the Social Exclusion Index and the variations in breast cancer mortality rates for women in Brazil from 1990 to 2011. ( $r=-0.75 ; p<0.001)$. Acre (AC), Alagoas (AL), Amapá (AP), Amazonas (AM), Bahia (BA), Ceará (CE), Distrito Federal (DF), Espírito Santo (ES), Goiás (GO), Maranhão (MA), Mato Grosso (MT), Mato Grosso do Sul (MS), Minas Gerais (MG), Pará (PA), Paraíba (PB), Paraná (PR); Pernambuco (PE), Piauí (PI), Rio de Janeiro (RJ), Rio Grande do Norte (RN), Rio Grande do Sul (RS), Rondônia (RO), Roraima (RR), Santa Catarina (SC), São Paulo (SP), Sergipe (SE), Tocantins (TO).

made of what is required by women and by healthcare services. Although the treatment options for breast cancer are effective, they unfortunately remain inaccessible to many women living in developing areas. Lack of care has resulted in unnecessary deaths. The unequal distribution of resources for breast cancer care and control for women living in the same country is unacceptable.

\section{Conclusions}

Although there has been a trend toward stabilization in female breast cancer mortality rates in Brazil, when the mortality rate of each state is analyzed individually, considerable inequalities are found, with rate decline or stabilization in states with higher socioeconomic levels and a substantial rate increase in those with lower socioeconomic levels. Reductions in these rates were found in the more developed states, possibly reflecting better healthcare.

\section{Limitations}

The use of the mortality data from the mortality data system is subject to correction due to an underregistration of deaths that is unfortunately common in less developed areas. The demographic database may contain errors that are inherent to data collection or to the methodology used to calculate population-based estimates. With respect to the breast cancer mortality rate, there are always limitations to its use when a considerable proportion of deaths take place without medical care or because of other poorly defined causes.

\section{Abbreviations}

APC: Annual percent change; AAPC: Average annual percent change; DATASUS: Ministry of Health's database; ICD: International Classification of Diseases; Cl: Confidence intervals; SEl: The Social Exclusion Index; HDI: Human Development Index; GBECAM: Brazilian Group for Studies in Breast Cancer.

\section{Competing interests}

Carolina Maciel Reis Gonzaga received a scholarship from CAPES (Coordenação de Aperfeiçoamento de Pessoal de Nivel Superior). None of the other authors have any conflicts of interest to declare.

\section{Authors' contributions}

CMRG conceived of the study and performed the statistical analysis. RFJ and MPC participated in its design and coordination. ALLS performed the statistical analysis. All authors read and approved the final manuscript.

\section{Authors' information}

Study conducted by the Goiás Mastology Research Network, Goiânia, Goiás, Brazil.

\section{Author details}

${ }^{1}$ Health Sciences, Federal University of Goiás (UFG), Goiânia, Brazil. ${ }^{2}$ Department of Obstetrics and Gynecology, Federal University of Goiás 
(UFG), Goiânia, Brazil. ${ }^{3}$ Hospital Araújo Jorge, Goiás Anticancer Association (ACCG), Goiânia, Brazil. ${ }^{4}$ International Prevention Research Institute (IPRI), Lyon, France. ${ }^{5}$ Federal University of Goiás (UFG), Goiânia, Brazil. ${ }^{6}$ Institute of Tropical Pathology and Public Health, Federal University of Goiás (UFG),

Goiânia, Brazil. ${ }^{7}$ Alameda das Rosas, 533, Setor Oeste, 74110-060 Goiânia, GO, Brazil.

Received: 10 June 2014 Accepted: 20 January 2015

Published online: 07 February 2015

\section{References}

1. Ferlay J, Soerjomataram I, Ervik M, Dikshit R, Eser S, Mathers C, et al. GLOBOCAN 2012 v1.0, Cancer Incidence and Mortality Worldwide: IARC Cancer Base No. 11 [Internet]. Lyon, France: International Agency for Research on Cancer; 2013. Available from: http://globocan.iarc.fr. Accessed 09 January 2014

2. Siegel R, Naishadham D, Jemal A. Cancer statistics, 2013. CA Cancer J Clin. 2013;63(1):11-30. PubMed PMID: 23335087.

3. Freitas-Junior R, Gonzaga CM, Freitas NM, Martins E, Dardes Rde C. Disparities in female breast cancer mortality rates in Brazil between 1980 and 2009. Clinics. 2012;67(7):731-7. PubMed PMID: 22892915.

4. Gonzaga CMR, Freitas-Junior R, Souza MR, Curado MP, Freitas NMA. Disparities in female breast cancer mortality rates between urban centers and rural areas of Brazil: Ecological time-series study. Breast 2014. In press http://dx.doi.org/ 10.1016/j.breast.2014.01.006

5. Singh GK, Miller BA, Hankey BF, Edwards BK. Area Socioeconomic Variations in U.S. Cancer Incidence, Mortality, Stage, Treatment, and Survival, 1975-1999, $\mathrm{NCl}$ Cancer Surveillance Monograph Series, Number 4. Bethesda, MD: National Cancer Institute, NIH Publication No 03-5417; 2003.

6. Anderson BO, Cazap E, El Saghir NS, Yip CH, Khaled HM, Otero IV, et al. Optimisation of breast cancer management in low-resource and middle-resource countries: executive summary of the Breast Health Global Initiative consensus, 2010. Lancet Oncol. 2011:12(4):387-98. PubMed PMID: 21463833.

7. Lee BL, Liedke PE, Barrios CH, Simon SD, Finkelstein DM, Goss PE. Breast cancer in Brazil: present status and future goals. Lancet Oncol. 2012;13(3):e95-102. PubMed PMID: 22381937.

8. DATASUS - Departamento de Informática do Sistema Único de Saúde [http://www2.datasus.gov.br/DATASUS/index.php]

9. Kim HJ, Fay MP, Feuer EJ, Midthune DN. Permutation tests for joinpoint regression with applications to cancer rates. Stat Med. 2000;19(3):335-51. PubMed PMID: 10649300

10. Ribeiro KB, Lopes LF, de Camargo B. Trends in childhood leukemia mortality in Brazil and correlation with social inequalities. Cancer. 2007;110(8):1823-31. PubMed PMID: 17786938

11. Bosetti C, Malvezzi M, Chatenoud L, Negri E, Levi F, La Vecchia C. Trends in cancer mortality in the Americas, 1970-2000. Ann Oncol. 2005;16(3):489-511. PubMed PMID: 15668262

12. Autier P, Boniol M, La Vecchia C, Vatten L, Gavin A, Hery C, et al. Disparities in breast cancer mortality trends between 30 European countries: retrospective trend analysis of WHO mortality database. BMJ. 2010;341: c3620. PubMed PMID: 20702548.

13. Shin HR, Boniol M, Joubert C, Hery C, Haukka J, Autier P, et al. Secular trends in breast cancer mortality in five East Asian populations: Hong Kong, Japan, Korea, Singapore and Taiwan. Cancer Sci. 2010;101(5):1241-6. PubMed PMID: 20219071.

14. Goss PE, Lee BL, Badovinac-Crnjevic T, Strasser-Weippl K, Chavarri-Guerra Y, St Louis J, et al. Planning cancer control in Latin America and the Caribbean. Lancet Oncol. 2013;14(5):391-436. PubMed PMID: 23628188.

15. Igene $\mathrm{H}$. Global health inequalities and breast cancer: an impending public health problem for developing countries. Breast J. 2008;14(5):428-34. PubMed PMID: 18821930

16. Simon SD, Bines J, Barrios $\mathrm{CH}$, et al. Clinical characteristics and outcome of treatment of Brazilian women with breast cancer treated at public and private institutions - the AMAZONE project of the Brazilian breast cance study group (GBECAM), San Antonio Breast Cancer Symposium 2009; San Antonio, TX, USA. 2009. Abstr 3082

\section{Submit your next manuscript to BioMed Central and take full advantage of:}

- Convenient online submission

- Thorough peer review

- No space constraints or color figure charges

- Immediate publication on acceptance

- Inclusion in PubMed, CAS, Scopus and Google Scholar

- Research which is freely available for redistribution

Submit your manuscript at www.biomedcentral.com/submit 